\title{
The effects of Fenton process on the removal of petroleum hydrocarbons from oily sludge in Shiraz oil refinery, Iran
}

\author{
Mehdi Farzadkia', Mansooreh Dehghani ${ }^{2 *}$ and Maryam Moafian²
}

\begin{abstract}
Background: Due to the high concentrations of total petroleum hydrocarbons (TPH) in oily sludge and their environmental hazards, the concern regarding their effects on health and the environment has increased. The main objective of this research was focused on evaluating the feasibility of using Fenton process in removing TPH in oily sludge from Shiraz oil refinery, Southern Iran.

Results: To determine optimum conditions, four different parameters were assessed at four different levels using Taguchi method. According to data, the optimum conditions were as follows: the reaction time of 1 hour, $\mathrm{H}_{2} \mathrm{O}_{2}$ to sample mass ratio of $15, \mathrm{H}_{2} \mathrm{O}_{2}$ to $\mathrm{Fe}$ (II) molar ratio of 10 and $\mathrm{pH}$ of 5. The maximum TPH reduction rate was $36.47 \%$. Because of the semi-solid nature of the sample and the hydroxyl radicals mainly generated in the aqueous solution, TPH reduction rate greatly improved by adding water. Ultimately, by adding $40 \mathrm{ml}$ water per gram of the oily sludge under optimized conditions, the reduction rate of $73.07 \%$ was achieved.
\end{abstract}

Conclusions: The results demonstrated that this method can be used as a pre-treatment method for the oily sludge. Moreover, a complementary treatment is necessary to reach the standard limit.

Keywords: Fenton process, Total petroleum hydrocarbon, Oily sludge, Shiraz oil refinery

\section{Background}

Crude oil contains saline, water, heavy hydrocarbons, and dirt. When crude oil is stored in refinery tanks, a dense phase is gradually formed at the bottom of the tanks called oily sludge. Considering the high concentrations of petroleum hydrocarbons in the created sludge at refineries, the California Environment Protection Agency has listed this compound as a hazardous material (K series) [1]. Petroleum hydrocarbons consist of different fractions of alkanes, alkenes, aromatic hydrocarbons and asphalts [2].

Most of these compounds cause cancer and mutations and have the potential of biological accumulation in living organisms. These compounds are resistant to biodegradation and stay in the environment for a long period of time. Disposal of the oily sludge into the environment is a threat for people as well as the environment. Therefore, the purification of the oily sludge

\footnotetext{
* Correspondence: mdehghany@sums.ac.ir

${ }^{2}$ Department of Environmental Health Engineering, School of Health, Shiraz University of Medical Sciences, Shiraz, Iran

Full list of author information is available at the end of the article
}

before releasing it to the environmental is inevitably crucial [3-5].

The removal of oil pollutants are often performed by physical or chemical processes. These methods are commonly expensive with the potential of producing byproduct pollutants [6]. Advanced oxidation processes are used for removing organic hydrocarbons. Fenton's method has more advantages comparing to other methods since it is cheaper, reduced reaction time and energy consumption, non-toxic nature of the compounds, and operation and control simplicity [7].

The basis of the Fenton method is the decomposition of $\mathrm{H}_{2} \mathrm{O}_{2}$ and the production of hydroxyl radicals in the presence of $\mathrm{Fe}^{3+}$ ions as a catalyst [8-10]. Studies have shown that produced hydroxyl radicals are capable of decomposing and degrading organic contaminants such as petroleum hydrocarbons [11-16].

$\mathrm{Lu}$ et al. studied the remediation of petroleumcontaminated soil using Fenton method. They concluded that Fenton method increased the efficiency of the biological process [17]. In another study, petroleum- 
Table 1 The chemical and physical properties of the oily sludge sample at Shiraz oil refinery

\begin{tabular}{|c|c|c|}
\hline Test & Test method & Result \\
\hline $\mathrm{SP}^{1}\left(15.56^{\circ} \mathrm{C}\right)$ & ASTM D 4052 & 0.9163 \\
\hline Water content (\%) & ASTM D 95 & 26 \\
\hline Wax content (\%) & UOP 46 & 33.3 \\
\hline Drop melting point $\left({ }^{\circ} \mathrm{C}\right)$ & IP 36 & 79 \\
\hline Sediment by extraction (\%) & ASTM D 473 & 10.5 \\
\hline Nickel content (\%) & AAS & 0.01 \\
\hline Vanadium content (\%) & AAS & $<0.01$ \\
\hline Iron content (\%) & AAS & 0.4 \\
\hline Lead content (\%) & AAS & $<0.01$ \\
\hline Sodium content (\%) & AAS & 0.3 \\
\hline $\mathrm{SiO}_{2}$ content (\%) & Gravimetric & 2.2 \\
\hline
\end{tabular}

1 specific gravity.

contaminated soil was treated using phosphate to increase the efficiency of the Fenton process but the reduction of more than $40 \%$ was not achieved [18]. The removal efficiency of polycyclic aromatic hydrocarbons (PAHs) was in the range of 70-98\% (depending on the chemical characteristics of PAHs) using the combined biodegradation and a modified Fenton method [19].

Since Fars (in Southern part of Iran) enjoys the top rank in oil refinery in the country in recent years, there is a concern regarding the effect of petroleum hydrocarbons in oily sludge on people's health and the environment. Therefore, the objectives of the study were to (i) evaluate the feasibility of using Fenton method in removing petroleum hydrocarbons in oily sludge obtained from Shiraz oil refinery, (ii) determine the optimum conditions using Taguchi method so that the standard limit can be achieved by further complementary treatment.

\section{Methods}

The oily sludge sample was obtained from the bottom of one of the crude oil tanks at Shiraz oil refinery and stored at $4^{\circ} \mathrm{C}$ until they were used. The tank was drained

Table 2 Tested parameters at four different levels

\begin{tabular}{lcccc}
\hline Parameters & \multicolumn{4}{c}{ Levels } \\
\cline { 2 - 5 } & $\mathbf{1}$ & $\mathbf{2}$ & $\mathbf{3}$ & $\mathbf{4}$ \\
\hline $\mathrm{H}_{2} \mathrm{O}_{2}$ to sample mass ratio & 5 & 10 & 15 & 20 \\
$\mathrm{H}_{2} \mathrm{O}_{2}$ to $\mathrm{Fe}(\mathrm{II})$ molar ratio & $0^{1}$ & 1 & 5 & 10 \\
Reaction time (hr) & 1 & 12 & 24 & 48 \\
$\mathrm{pH}$ & 3 & 5 & $7^{2}$ & 9 \\
\hline
\end{tabular}

1 No iron added.

$2 \mathrm{pH}$ of oily sludge. after 2 years because of some repairs. The sample kept at standard conditions [20]. Data regarding the chemical and physical properties of oily sludge sample is summarized in Table 1.

The standard methods (State Department of Natural Resources, Texas, US) was applied to measure TPH [20]. American Public Health Association (APHA) was used to determine the amount of humidity and iron [21]. The water content was measured by the Karl Fischer method [22].

According to Table 1, TPH concentration, iron and water content were high in the oily sludge sample while the moisture content was low. PROFEPA reported a maximum allowable TPH concentration of $2000 \mathrm{ml} / \mathrm{kg}$ in soil [23]. Due to very high concentrations of TPH in the oily sludge sample, it is very important to select a proper treatment method. In this study we used Taguchi method to determine the optimum conditions. This method is based on the effect of different parameters and the amount of response. The optimization in experimental design was performed by a limited number of tests [24-26].

The experiment was performed at a bench-scale batch reactor mode at room temperature and normal pressure. The effect of different parameters $\left(\mathrm{H}_{2} \mathrm{O}_{2}\right.$ to sample mass ratio, $\mathrm{H}_{2} \mathrm{O}_{2}$ to $\mathrm{Fe}$ (II) molar ratio, reaction time, and $\mathrm{pH}$ ) on the reduction rate of TPH were determined at four different levels. The retention time $(1,12,24$, and 48 hours), the molar ratio of $\mathrm{H}_{2} \mathrm{O}_{2}$ to $\mathrm{Fe}$ (II) $(1,5$, and 10), the mass ratio of $\mathrm{H}_{2} \mathrm{O}_{2}$ to sludge $(5,10,15$, and 20) and $\mathrm{pH}(3,5,7$, and 9) were assessed. Table 2 summarizes parameters at four different levels. Qualitek-4 software was used to design the test. The sixteen experiments were performed at two replications and the fifth factorial was used to calculate degree of freedom for determining the error [27]. Control (without Fenton's reagent) was also used to show the effect of volatile organic content in the oily sludge.

All chemicals were purchased from Merck (Germany). Because of the low water content of the oily sludge sample, distilled water ( $1 \mathrm{ml}$ per $0.5 \mathrm{~g}$ oily sludge) was added to the sample and the $\mathrm{pH}$ was adjusted by sodium hydroxide $(\mathrm{NaOH})$ and sulphuric acid $\left(\mathrm{H}_{2} \mathrm{SO}_{4}\right) . \mathrm{FeSO}_{4} \cdot 7 \mathrm{H}_{2} \mathrm{O}(99 \%$ purity) and $\mathrm{H}_{2} \mathrm{O}_{2}$ (30\% purity) were used. After the specified reaction time, the remaining TPH was measured by Shimadzu Model gas chromatography, Flame Ionization Detector.

\section{Results and discussion}

Table 3 shows the designed experiments and their results. As shown, experiment 12 had the highest response rate (mean $35.02 \%$ ). The lowest efficiency was related to experiment $14(1.36 \%)$. 
Table 3 The experimental design for the reduction rate of TPH from oily sludge sample at Shiraz oil refinery using Taguchi method

\begin{tabular}{|c|c|c|c|c|c|c|}
\hline \multirow{2}{*}{$\begin{array}{l}\text { Number of } \\
\text { experiment }\end{array}$} & \multicolumn{4}{|c|}{ Levels of different variables } & \multicolumn{2}{|c|}{ TPH reduction rate $(\%)$} \\
\hline & $\mathrm{H}_{2} \mathrm{O}_{2}$ to sample mass ratio & $\mathrm{H}_{2} \mathrm{O}_{2}$ to $\mathrm{Fe}(\mathrm{II})$ molar ratio & Retention time & $\overline{\mathrm{pH}}$ & $1^{\text {st }}$ repetition & $2^{\text {nd }}$ repetition \\
\hline 1 & 3 & 3 & 3 & 3 & 14.1 & 14.26 \\
\hline 2 & 3 & 1 & 3 & 3 & 8.76 & 8.85 \\
\hline 3 & 1 & 4 & 4 & 3 & 21.41 & 21.53 \\
\hline 4 & 2 & 1 & 2 & 4 & 4.58 & 46 \\
\hline 5 & 4 & 1 & 4 & 2 & 11.31 & 11.36 \\
\hline 6 & 4 & 4 & 2 & 1 & 9.41 & 9.51 \\
\hline 7 & 2 & 3 & 4 & 1 & 15 & 15.05 \\
\hline 8 & 4 & 2 & 3 & 1 & 34.99 & 35.05 \\
\hline 9 & 2 & 2 & 1 & 3 & 7.66 & 7.74 \\
\hline 10 & 4 & 4 & 1 & 4 & 23.28 & 23.24 \\
\hline 11 & 2 & 4 & 3 & 2 & 19.87 & 19.87 \\
\hline 12 & 3 & 2 & 4 & 4 & 35.1 & 34.97 \\
\hline 13 & 4 & 3 & 2 & 3 & 20.89 & 20.99 \\
\hline 14 & 1 & 3 & 3 & 4 & 1.32 & 1.41 \\
\hline 15 & 1 & 1 & 1 & 1 & 6.2 & 6.3 \\
\hline 16 & 1 & 2 & 2 & 2 & 22.54 & 22.57 \\
\hline
\end{tabular}

The effect of $\mathrm{pH}$ on the reduction rate of TPH in the oily sludge sample at Shiraz oil refinery

The variations of $\mathrm{pH}$ on $\mathrm{TPH}$ reduction rate were shown on Figure 1. The rate of TPH reduction increased quickly when the $\mathrm{pH}$ increased from 3 to 5 and then reaching constant with relative slower rate up to $\mathrm{pH}$ equal 7 after that the reduction rate decreased when the $\mathrm{pH}$ increased to 9 .

Due to at the production of $\mathrm{Fe}\left(\mathrm{H}_{2} \mathrm{O}\right)^{2+}$ at very low $\mathrm{pH}$ $(<2.5)$, the rate of TPH reduction decreased. Fe $\left(\mathrm{H}_{2} \mathrm{O}\right)^{2+}$ reacts with hydrogen peroxide and cause the reduction of hydroxyl radicals. Moreover, the reaction between $\mathrm{Fe}^{3+}$ ions and hydrogen peroxide is inhibited $[28,29]$. At $\mathrm{pH}<4$ the decomposition of pollutants is reduced because of the reduction of free iron ions in the solution and this can be caused by the complex formation of $\mathrm{Fe}^{2+}$ ions and buffer or the production of ferric hydroxide precipitate [28,29]. In alkaline conditions, the lower reduction rate is experienced as $\mathrm{Fe}^{2+}$ changes to $\mathrm{Fe}(\mathrm{OH})_{3}$. Fe $(\mathrm{OH})_{3}$ reacts with $\mathrm{H}_{2} \mathrm{O}_{2}$ and inhibits the production of $\mathrm{OH}$ radicals. Moreover, studies have shown that the oxidative potential of $\mathrm{OH}$ radicals reduced as $\mathrm{pH}$ increased [28,29].

Many studies have shown that the optimum conditions for the Fenton process is the acidic condition. By adding the Fenton's reagent, $\mathrm{pH}$ is reduced. This $\mathrm{pH}$ reduction has been accompanied with the production of intermediates such as carboxylic acid; therefore, the maximum reduction rate occurred at higher $\mathrm{pH}$.

Kumar et al. found that the removal efficiency of chemical oxygen demand (COD) was $60 \%$ at $\mathrm{pH}=4.27$ for the

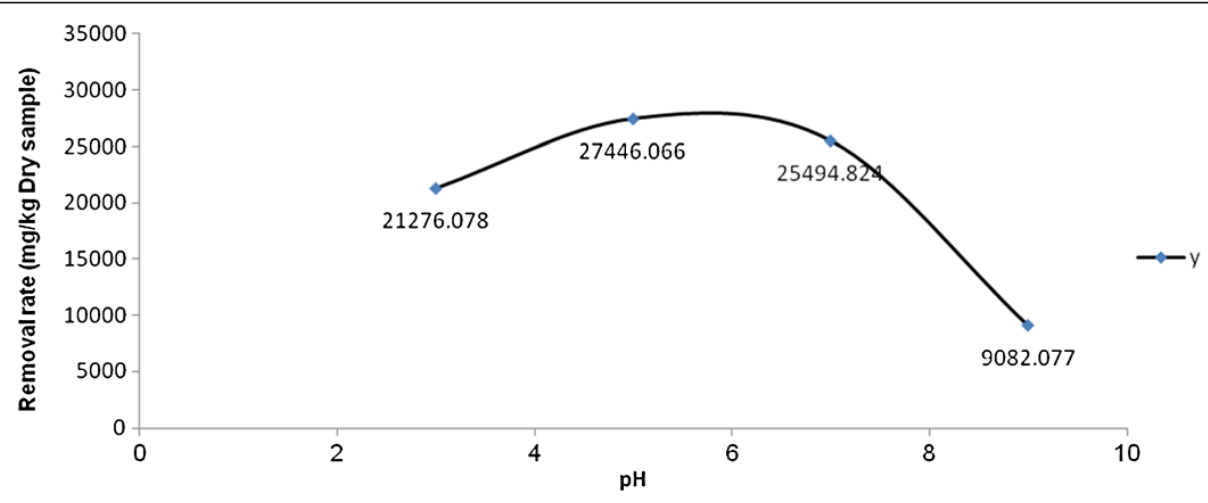

Figure 1 Effect of $\mathrm{pH}$ on the reduction rate of TPH from the oily sludge sample at Shiraz oil refinery. 


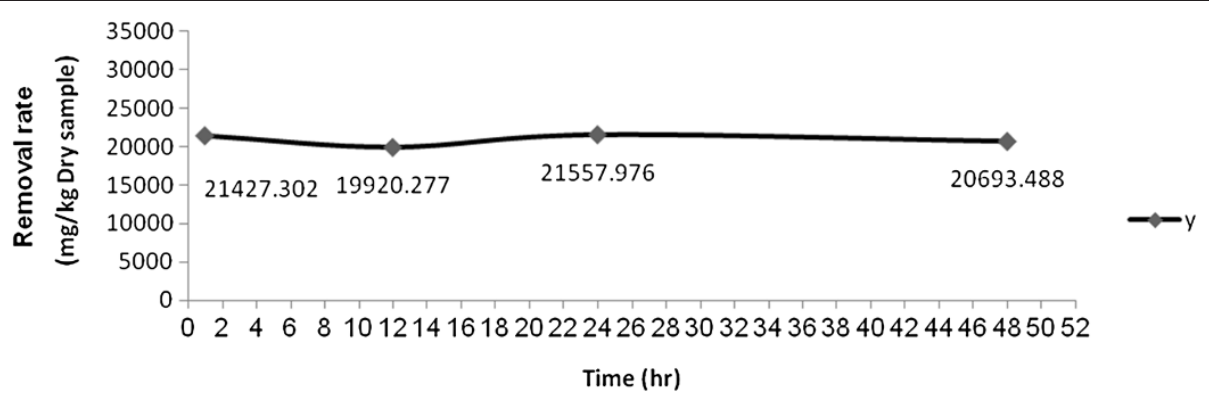

Figure 2 Effect of reaction time on TPH removal from the oily sludge sample at Shiraz oil refinery.

coffee pulping wastewater using the Fenton process. If $\mathrm{pH}$ was increased to 6.4, the removal efficiency was increased to $83.9 \%$ [30]. Barbano-Arturo et al., assessed the effect of $\mathrm{pH}$ on the degradation of methyl tertiary butyl ether (MTBE) using the Fenton process. This study associated the $\mathrm{pH}$ reduction during the reaction to the production of carboxylic acids [31].

\section{The effect of reaction time on the reduction rate of TPH} in the oily sludge sample at Shiraz oil refinery

Figure 2 shows the effect of time on the reduction rate of TPH. As shown, the maximum reduction rate was achieved at the reaction time of $1 \mathrm{hr}$ and then remains constant.

One of the most advantages of the Fenton process is that the reaction is very fast compared with other oxidation methods. However, the reaction time depends mostly on the type of wastewater and the amount of catalyst was used. An optimum reaction time of 90 minutes was achieved for the treatment of landfill leachate using the Fenton method. Fenton process effectively degraded high molecular weight in landfill leachate in 30 minutes [32]. The removal efficiency of $95 \%$ was achieved for TOC removal at a reaction time of 60 minutes for bamboo industry wastewater [33].
The effect of ratio of peroxide to sample on the reduction rate of TPH in the oily sludge sample at Shiraz oil refinery Figure 3 shows the effect of ratio of peroxide to sample on TPH reduction rate. According to Figure 3, the TPH reduction rate increased when the mass ratio increased from 5 to 15 , but its reduction decreased when the mass ratio increased from 15 to 20 . Therefore, peroxide concentration plays an important role on the reduction of TPH. Oily sludge contains other compounds such as heavy metals, salt, water, and also many other unknown compounds that can affect the Fenton process. Since these compounds consumed hydrogen peroxide, determining the exact amount of hydrogen peroxide is highly important. Using the higher amount of hydrogen peroxide, more than required concentration for the optimum condition, increased the COD in the effluent. Moreover, the presence of hydrogen peroxide in the effluent has toxic effect on microorganisms and decreases the feasibility of biodegradation rate. Using low concentration of $\mathrm{H}_{2} \mathrm{O}_{2}$ makes the Fenton process economically acceptable [32,34]. The excess amount of $\mathrm{H}_{2} \mathrm{O}_{2}$ acts as hydroxyl radical's scavenger $\left(\mathrm{HO}_{2}{ }^{\circ}\right)$ and reduced the reaction rate $[35,36]$.

The required concentration of $\mathrm{H}_{2} \mathrm{O}_{2}$ for the reaction depends on the concentration and type of the pollutant. Using combined Fenton and microbial processes in a

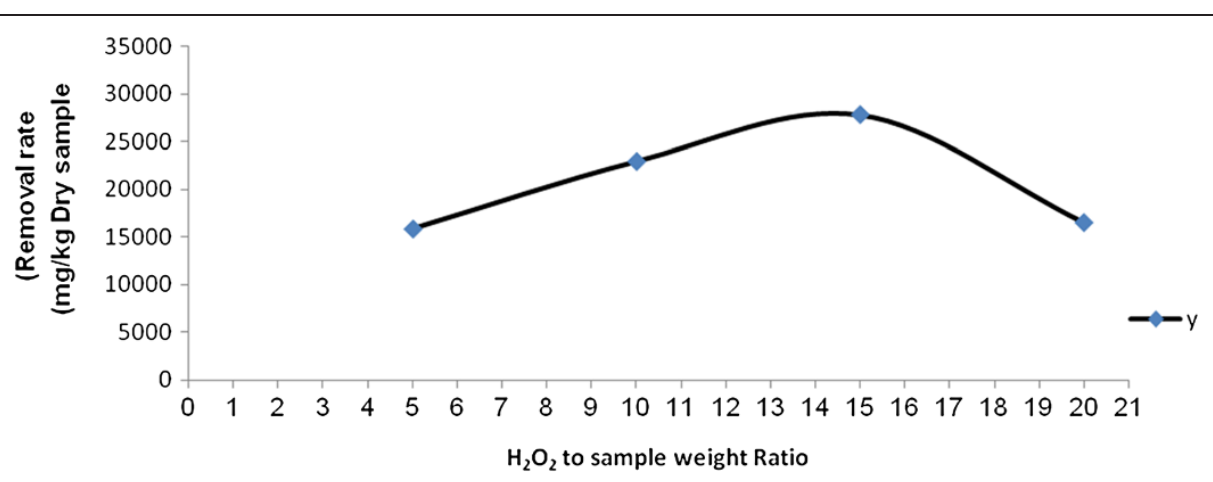

Figure 3 The effect of $\mathrm{H}_{2} \mathrm{O}_{2}$ on the reduction rate of TPH from the oily sludge sample at Shiraz oil refinery. 


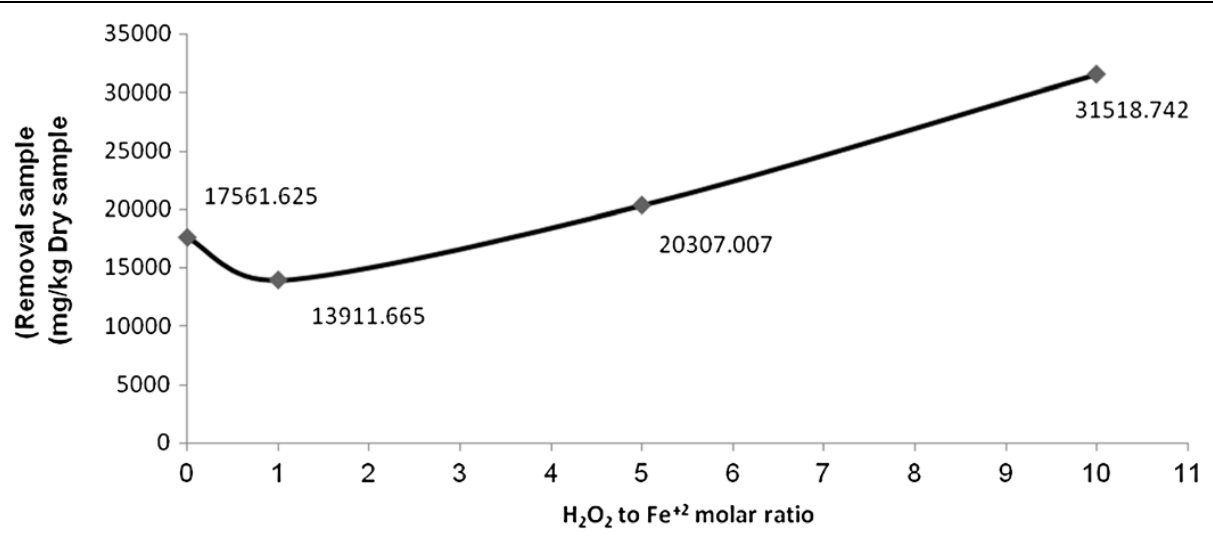

Figure 4 The effect of molar ratio of $\mathrm{H}_{2} \mathrm{O}_{2}$ to $\mathrm{Fe}$ (II) on the reduction rate of TPH from the oily sludge sample at Shiraz oil refinery.

contaminated soil with benzoanthracene, the optimum amount of $\mathrm{H}_{2} \mathrm{O}_{2}$ was $0.3 \mathrm{ml}$ per gram soil [37].

The effect of molar ratio of $\mathrm{H}_{2} \mathrm{O}_{2}$ to $\mathrm{Fe}$ (II) on the reduction rate of $\mathrm{TPH}$ in the oily sludge sample at Shiraz oil refinery

The molar ratio of $\mathrm{H}_{2} \mathrm{O}_{2}$ to $\mathrm{Fe}$ (II) was tested at three levels of 1, 5, and 10. The oxidation of the pollutant occurred in the presence of $\mathrm{H}_{2} \mathrm{O}_{2}$ with or/ without the addition of iron to the sample. To examine the effect of $\mathrm{H}_{2} \mathrm{O}_{2}$ on the reduction rate of TPH, one of the levels was done without the addition of Fe (II). Figure 4 shows the effect of molar ratio of $\mathrm{H}_{2} \mathrm{O}_{2}$ to $\mathrm{Fe}$ (II) on the reduction rate of $\mathrm{TPH}$ in the oily sludge sample at Shiraz oil refinery at different levels. According to this Figure, using $\mathrm{H}_{2} \mathrm{O}_{2}$ without addition of Fe (II) did not have a considerable effect on the TPH reduction. In addition adding Fe (II) with the ratio of $1 / 1$ did not increase the reduction. However, by increasing this ration to 5 and 10 , the reduction rate considerably increased.

The molar ratio of $\mathrm{H}_{2} \mathrm{O}_{2}$ to $\mathrm{Fe}$ (II) is an important factor in the Fenton process. Lower ratios reduce the removal efficiency because of the reaction between

Table 4 ANOVA results and results analysis using the Taguchi method

\begin{tabular}{lcccc}
\hline Variable & $\begin{array}{c}\text { Degree of } \\
\text { freedom }\end{array}$ & $\begin{array}{c}\text { Variance } \\
\text { (V) }\end{array}$ & $\begin{array}{c}\text { Variance } \\
\text { ratio (F) }\end{array}$ & $\begin{array}{c}\text { Distribution } \\
\text { percentage } \\
\text { (P \%) }\end{array}$ \\
\hline $\begin{array}{l}\mathrm{H}_{2} \mathrm{O}_{2} \text { to } \\
\text { sample mass } \\
\text { ratio }\end{array}$ & 3 & 256330804.3 & 3.714 & 11.005 \\
$\mathrm{H}_{2} \mathrm{O}_{2}$ to Fe(II) & 3 & 461515155.048 & 6.687 & 23.061 \\
molar ratio & & 3696500.439 & 0.053 & 0 \\
Reaction time & 3 & 543321759.458 & 70872 & 27.867 \\
pH & 3 & 59016758.195 & - & 38.067 \\
Error & 19 & - & - & 100.00 \\
Total & 31 & - & & \\
\hline
\end{tabular}

excess Fe ions and hydroxyl radicals leading to the production of $\mathrm{Fe}(\mathrm{OH})_{3}$. The excess $\mathrm{Fe}$ would further increase the turbidity [26,38]. Because of the reaction between $\mathrm{H}_{2} \mathrm{O}_{2}$ and hydroxyl radicals, the higher ratios reduced the removal efficiency [38-41]. Studies have reported the different molar ratios of $\mathrm{H}_{2} \mathrm{O}_{2}$ to $\mathrm{Fe}$ (II) as the optimum ration. The amount of this ration depends on the type, concentration, and the mineral contents of the pollutant $[42,43]$.

The Fenton process and microbial degradation was applied to remove PAHs. The optimum ration of $\mathrm{H}_{2} \mathrm{O}_{2}$ to $\mathrm{Fe}$ (II) was 10 to 1 [42]. Another study reported a similar molar ratio of $\mathrm{H}_{2} \mathrm{O}_{2}$ to $\mathrm{Fe}$ (II) 10 to 1 for removing hydrocarbons with 2-4 rings [44]. The same ratio was also obtained for the removal of aromatic hydrocarbons from soil [45].

Table 4 shows the results of analysis of variance of ANOVA. Since the four parameters were studied at four levels, the degree of freedom for comparing the response rates at 4 levels was 3 . According to Table 4, the order of studied parameters regarding the effectiveness on the reaction rate was as follows: $\mathrm{pH}, \mathrm{H}_{2} \mathrm{O}_{2}$ to $\mathrm{Fe}$ (II) molar ratio, $\mathrm{H}_{2} \mathrm{O}_{2}$ to sample mass ratio. The reaction time of more than one hour did not have a significant effect on the Fenton process for removing TPH from the oily sludge.

Using Figures and the ANOVA results, the relative optimum conditions can be obtained for the maximum

Table 5 The optimal conditions for maximum reduction rate of TPH in the oily sludge sample at Shiraz oil refinery

\begin{tabular}{lc}
\hline Variables & Optimal level \\
\hline $\mathrm{H}_{2} \mathrm{O}_{2}$ to sample mass ratio & 15 \\
$\mathrm{H}_{2} \mathrm{O}_{2}$ to $\mathrm{Fe}(\mathrm{II})$ molar ratio & 10 \\
Reaction time (hr) & 1 \\
$\mathrm{pH}$ & 5 \\
\hline
\end{tabular}


Table 6 The effect of moisture content on the reduction rate of TPH from the oily sludge sample at Shiraz oil refinery

\begin{tabular}{lccc}
\hline $\begin{array}{l}\text { Added amounts } \\
\text { of water }\end{array}$ & $\begin{array}{c}\text { TPH removal } \\
\text { percentage } \\
\left(\mathbf{1}^{\text {st }} \text { repetition }\right)\end{array}$ & $\begin{array}{c}\text { TPH removal } \\
\text { percentage } \\
\left(\mathbf{2}^{\text {nd }} \text { repetition }\right)\end{array}$ & $\begin{array}{c}\text { Removal } \\
\text { mean (\%) }\end{array}$ \\
\hline 5 & 40.07 & 40.46 & 40.26 \\
10 & 55.56 & 55.43 & 55.49 \\
20 & 72.98 & 73.17 & 73.07 \\
30 & 74.12 & 73.89 & 74.00 \\
\hline
\end{tabular}

reduction rate of TPH in the oily sludge sample at Shiraz oil refinery (Table 5).

The optimum TPH removal conditions were determined by data analysis. Based on the analyses, the predicted percentage rate was $35.28 \%$. According to data in this study, $\mathrm{TPH}$ reduction rate of $36.47 \%$ was obtained which is very close to the predicted results by Taguchi method.

\section{The effect of available water content on the reduction} rate of TPH in the oily sludge sample at Shiraz oil refinery Since hydroxyl radicals are formed in the aqueous phase [8], the effect of dilution was evaluated in this study. Investigation on soil samples showed that pollutant should initially be separated from the solid phase then the generated hydroxyl radicals in an aqueous phase oxidize the pollutants $[46,47]$. Initially, dilution was done by adding $1 \mathrm{ml}$ water to $0.5 \mathrm{~g}$ sample. Although this amount of water was adequate for producing a solid/solution suspension, water was trapped by the sample so that the moisture content of the sample was considerably reduced. In order to increase the moisture content of the sample, different amounts of distilled water $(5,10,20$, and $30 \mathrm{ml}$ distilled water) was added to reach the optimum condition for removal of TPH from oily sludge sample. Table 6 summarizes the data obtained from the reduction rate of TPH in the oily sludge sample at Shiraz oil refinery at different moisture content. According to Table 6, adding $20 \mathrm{ml}$ water increased the reduction rate of TPH up to $73.03 \%$. Increasing water content to $30 \mathrm{ml}$ increased the $\mathrm{TPH}$ reduction rate only by $1 \%$. Therefore, the optimum amount of added water was $20 \mathrm{ml}$ to obtain the highest $\mathrm{TPH}$ reduction rate.

\section{Evaporation of TPH}

TPH reduction rate in the control reactor was $1.31 \%$. Since all the experiments were performed at room temperature, the evaporation of TPH was quite low. Therefore, it can be concluded that Fenton's reagent was played the main role in TPH reduction. Data obtained from this study are consistent with other studies $[48,49]$.
The effect of other pollutants present in the oily sludge on the reduction rate of TPH in the oily sludge sample at Shiraz oil refinery

According to the characteristics of the oily sludge sample (Table 1), it can be assumed that generated hydroxyl radicals were used for reduction of TPH and oxidation of other pollutants such as heavy metals as well.

\section{Conclusions}

Using Taguchi method, the optimum conditions for the maximum reduction rate of TPH in oily sludge were achieved. The results demonstrated that the most effective parameters on the performance of the Fenton process were as follows: $\mathrm{pH}$, the mass ratio of $\mathrm{H}_{2} \mathrm{O}_{2}$ to sample, the molar ratio of $\mathrm{H}_{2} \mathrm{O}_{2}$ to $\mathrm{Fe}$ (II), and the reaction time. The optimum condition of $\mathrm{pH}$, the mass ratio of $\mathrm{H}_{2} \mathrm{O}_{2}$ to sample, and the molar ratio of $\mathrm{H}_{2} \mathrm{O}_{2}$ to $\mathrm{Fe}$ (II) were 5, 15, and 10 , respectively. The reduction rate of TPH was $36.47 \%$ at optimum condition. Increasing the moisture content by diluting with water had a very effective role in enhancing the reduction rate up to $73.07 \%$. Ultimately, the effluent TPH was $35 \mathrm{~g} / \mathrm{kg}$. This method can be a suitable pre-treatment method for treating oily sludge and adding a complementary treatment stage is necessary for reaching the desired standards.

\section{Competing interests}

The authors declare that they have no competing interests.

\section{Authors' contributions}

The overall implementation of this study including design, experiments and data analysis, and manuscript preparation were the results of efforts by corresponding author. All authors have made extensive contribution into the review and finalization of this manuscript. All authors read and approved the final manuscript.

\section{Acknowledgments}

The authors appreciate the Deputy of Research and Technology of Shiraz University of Medical Sciences for its financial support for the research project of 91-6170. This article is extracted from the Master's thesis.

\section{Author details}

${ }^{1}$ Department of Environmental Health Engineering, Iran University of Medical Sciences, Tehran, Iran. ${ }^{2}$ Department of Environmental Health Engineering, School of Health, Shiraz University of Medical Sciences, Shiraz, Iran.

\section{Received: 6 April 2013 Accepted: 7 January 2014}

Published: 14 January 2014

\section{References}

1. California Environmental Protection Agency: California petroleum refinery hazardous waste source reduction 2002 assessment report, Department of Toxic Substances Control. USA, California: Office of Pollution Prevention and Technology Development; 2006.

2. Wauquier JP: Petroleum Refining: Crude Oil, Petroleum Products, Process Flow sheets, Volume chap. 1. Paris: Institute Français du Pétrole, French; 1995.

3. TEPA (Taiwan Environmental Protection Administration): A research on the determination of the TPHs pollution levels in soil. Taiwan: Technical Report; 2003

4. Sarkar D, Ferguson M, Datta R, Birnbaum S: Bioremediation of petroleum hydrocarbons in contaminated soils: comparison of biosolids addition, carbon supplementation, and monitored natural attenuation. Environ Pollut 2005, 136:187-195 
5. CCME (Canadian Council of Ministers of the Environment): Canada-wide standards for Petroleum Hydrocarbons (PHCS) in soil: Scientific RationaleSupporting Technical Document. Winnipeg-Manitoba; 2000:310-312.

6. Xu N, Wang W, Han P, Lu X: Effects of ultrasound on oily sludge deoiling. J Hazard Mater 2009, 171:914-917.

7. Vanina F, Delteil C, Padellec Y, Camel V: Removal of sorbed polycyclic aromatic hydrocarbons from soil, sludge and sediment samples using the Fenton's reagent process. Chemosphere 2005, 59:1427-1437.

8. Yoon J, Lee $Y$, Kim S: Investigation of the reaction pathway of $\mathrm{OH}$ radicals produced by Fenton oxidation in the conditions of wastewater treatment. Water Sci Technol 2001, 44(5):15-21.

9. Lu MC, Lin CJ, Liao CH, Ting WP, Huang RY: Influence of $\mathrm{pH}$ on the dewatering of activated sludge by Fenton's reagent. Water Sci Technol 2001, 44(10):327-332.

10. Lin G, Nie JY, Zhu NW, Wang L, Yuan HP, Shou Z: Enhanced Fenton's degradation of real naphthalene dye intermediate wastewater containing 6-nitro-1-diazo-2-naphthol-4-sulfonic acid: a pilot scale study. J Chem Eng 2012, 189-190:108-116.

11. Yun Whan K, Kyung-Yub H: Effects of reaction conditions on the oxidation efficiency in the Fenton process. Water Res 2000, 34:2786-2790.

12. Neyens E, Baeyens J: A review of classic Fenton's peroxidation as an advanced oxidation technique. J Hazard Mater 2003, 98:33-50.

13. Sung-Ho K, Watts RJ, Choi JH: Treatment of petroleum-contaminated soils using iron mineral catalyzed hydrogen peroxide. Chemosphere 1998 , 37:1473-1482.

14. Yeh CK, Wu HM, Chen TC: Chemical oxidation of chlorinated nonaqueous phase liquids by hydrogen peroxide in natural sand systems. J Hazard Mater 2003, 96:29-51.

15. Ahad JME, Slater GF: Carbon isotope effects associated with Fenton-like degradation of toluene: potential for differentiation of abiotic and biotic degradation. Sci Total Environ 2008, 401:194-98.

16. Chamarro E, Marco A, Esplugas S: Use of Fenton reagent to improve organic chemical biodegradability. Water Res 2001, 35:1047-1051.

17. Mang L, Zhongzhi Z, Wei Q, Xiaofang W, Yueming G, Qingxia M, Yingchun $\mathrm{G}$ : Remediation of petroleum-contaminated soil after composting by sequential. Treatment with Fenton-like oxidation and biodegradation. Bioresource Tech 2010, 101:2106-2113.

18. Watts RJ, Dilly SE: Evaluation of iron catalysis for the Fenton-like remediation of diesel-contaminated soils. J Hazard Mater 1996, 51:209-224.

19. Nam K, Rodrigeuz W, Kukor JJ: Enhanced degradation of polycyclic aromatic hydrocarbons by biodegradation combined with a modified Fenton reaction. Chemosphere 2001, 45:11-20.

20. TNRCC: Standard Test Method for Total petroleum Hydrocarbon, Method 1005. 3rd edition. Texas, USA: Texas Natural Resources Conservation Commission; 2001.

21. APHA: Standard Methods for the Examination of Water and Wastewater. 17th edition. Washington, DC, USA: American Public Health Association; 2005.

22. ASTM D 4377: Standard Test Method for Water in Crude Oils by Potentiometric Karl Fischer Titration, Annual Book of ASTM Standards, vol. 11.05. West Conshocken, Philadelphia, USA: American Society for Testing and Materials, Internationa; 2002.

23. PROFEPA (2000) internet. http:/ www.profepa.gob,mx/saa/audita43.html.

24. Sadrzadeh M, Mohammadi T: Sea water desalination using electrodialysis. Desalination 2008, 221:440-447

25. Chou CS, Yang RY, Chen JH, Chou SW: The optimal conditions for preparing the lead-free piezoelectric ceramic of Bi0.5 Na0.5TiO3 using the Taguchi method. Powder Technol 2010, 199:264-271.

26. Zhang $\mathrm{H}$, Choi HJ, Canazo P, Huang CP: Multivariate approach to the Fenton process for the treatment of landfill leachate. J Hazard Mater 2009, 161:1306-1312.

27. Nutec I: Qualitek-4 user manual, Ref. Generic: Type; 2011.

28. Aliabadi M, Mirarefin SM, Mogadam Rezaee M: Reduction of polluted industrial wastewater by advance oxidation process. J Env Adv Res 2008, 2:49-53.

29. Munter R: Advanced oxidation processes-current status and prospects. Proc Estonian Acad Sci Chem 2001, 50(2):59-80.

30. Kumar BM, Ulavi SU, Ramesh HS, Asha G, Pallavi R: Pretreatment of coffee pulping wastewater by Fenton's reagent. Indian J Chem Technol 2012, 19:213-217
31. Burbano AA, Dionysiou DD, Suidan MT, Richardson TL: Oxidation kinetics and effect of $\mathrm{pH}$ on the degradation of MTBE with Fenton reagent. Water Res 2005, 39:107-118.

32. Zhang $\mathrm{H}$, Choi $\mathrm{HJ}$, Huang $\mathrm{CP}$ : Optimization of Fenton process for the treatment of landfill leachate. J Hazard Mater 2005, B125:166-174.

33. Dong-Lei W, Wei W, Qing-Wen G, Yan-Hong S: Combined Fenton-SBR process for bamboo industry wastewater treatment. Chem Eng J 2013, 214:278-284.

34. Tengrui L, Harbawi AA, Jun Z, Bo LM: The effect and its influence factors of the Fenton process on the old landfill leachate. J App/ Sci 2007, 7(5):724-727.

35. Dilaconi C, Ramadori R, Lopez A: Combined biological and chemical degradation for treating a mature municipal landfill leachate. J Biol Eng 2006, 31:118-124.

36. Talinli I, Dutta K, Mukhopadhray S, Bhattacharjee S, Chaudhuri B: Chemical oxidation of methylene blue using a Fenton-like reaction. $J$ Hazard Mater 2001, 84:57-71.

37. Lee $\mathrm{BD}$, Hosomi M: A hybrid Fenton oxidation-microbial treatment for soil contaminated with benzoanthracene. Chemosphere 2001, 43:1127-1132.

38. Juteau P, Bisaillon JG, Lepine F, Ratheau V, Beaudet R, Villemur R: Improving the biotreatment of hydrocarbons-contaminated soils by addition of activated sludge taken from the wastewater treatment facilities of an oil refinery. Biodegradation 2003, 14:31-40.

39. Lin SS, Gurol MD: Catalytic decomposition of hydrogen peroxide on iron oxide: kinetics, mechanism, and implications. Environ Sci Technol 1998, 32:1417-1423.

40. Venkatadri R, Peters RW: Chemical oxidation technologies: ultraviolet light/hydrogen peroxide, Fenton's reagent, and titanium dioxide-assisted photocatalysis, Hazard. Waste Hazard Mater 1993, 10:107-131.

41. Jiang $Y$, Waite TD: Degradation trace contamination using coupled sonochemistry and Fenton's reagent. Water Sci Technol 2003, 47:85-92.

42. Nam K, Rodriguez W, Kukor JJ: Enhanced degradation of polycyclic aromatic hydrocarbons by biodegradation combined with a modified Fenton reaction. Chemosphere 2001, 42:11-20.

43. Zhang $\mathrm{H}$, Choi HJ, Huang CP: Treatment of landfill leachate by Fenton's reagent in continuous stirred tank rector. J Hazard Mater 2006, B136:618-623.

44. Tang WZ, Huang CP: 2, 4 Dichlorophenol oxidation kinetics by Fenton's reagent. Environ Technol 1996, 17:1371-1378.

45. Goi A, Trapido M: Degradation of polycyclic aromatic hydrocarbons in soil: the Fenton reagent versus ozonation. Environ Technol 2004, 25:155-164.

46. Watts RJ, Udell MD, Kong S, Leung SW: Fenton-like soil remediation catalyzed by naturally occurring iron minerals. Environ Eng Sci 1999, 16(1):93-103.

47. Sedlak DL, Andren AW: The effect of sorption on the oxidation of polychlorinated biphenyls (PCBs) by hydroxyl radical. Water Res 1994, 28(5):1207-1215

48. Loehr RC, Smith JA, Corsi RL: VOC and SVOC emissions from slurry and solid phase bioremediation processes. Pract Period Hazard Toxic Radioact Waste Manage 2005, 5:211-224.

49. Namkoong W, Hwang EY, Park JS, Choi JY: Bioremediation of diesel-contaminated soil with composting. Environ Pollut 2002, 119:23-31.

doi:10.1186/2052-336X-12-31

Cite this article as: Farzadkia et al:: The effects of Fenton process on the removal of petroleum hydrocarbons from oily sludge in Shiraz oil refinery, Iran. Journal of Environmental Health Science \& Engineering 2014 12:31. 